\title{
Intracranial Arterial Dolichoectasia
}

\author{
Victor J. Del Brutto ${ }^{1 *}$, Jorge G. Ortiz ${ }^{2}$ and José Biller ${ }^{2}$ \\ ${ }^{1}$ Department of Neurology, Pritzker School of Medicine, University of Chicago, Chicago, IL, United States, ${ }^{2}$ Department of \\ Neurology, Stritch School of Medicine, Loyola University Chicago, Maywood, IL, United States
}

An increased diameter (ectasis) and/or long and tortuous course (dolichosis) of at least one cerebral artery define intracranial arterial dolichoectasia (IADE). IADE could be detected incidentally or may give rise to an array of neurological complications including ischemic stroke, intracranial hemorrhage, or compression of surrounding neural structures. The basilar artery is preferentially affected and has been studied in more detail, mainly due to the presence of accepted diagnostic criteria proposed by Smoker and colleagues in 1986 (1). Criteria for the diagnoses of dolichoectasia in other cerebral arteries have been suggested. However, they lack validation across studies. The prevalence of IADE is approximately $0.08-6.5 \%$ in the general population, while in patients with stroke, the prevalence ranges from 3 to $17 \%$. Variations among case series depend on the characteristics of the studied population, diagnostic tests used, and diagnostic criteria applied. In rare instances, an underlying hereditary condition, connective tissue disorder, or infection predispose to the development of IADE. However, most cases are

\section{OPEN ACCESS}

Edited by:

Ayrton R. Massaro,

Hospital Sirio-Libanes, Brazil

Reviewed by:

Susanne Wegener,

University of Zurich, Switzerland

Robbert-Jan Van Hooff,

Universitair Ziekenhuis Brussel,

Belgium

*Correspondence:

Victor J. Del Brutto

victor.delbruttoandrade@ uchospitals.edu

Specialty section:

This article was submitted to Stroke, a section of the journal

Frontiers in Neurology

Received: 08 May 2017 Accepted: 03 July 2017

Published: 17 July 2017

Citation:

Del Brutto VJ, Ortiz JG and Biller J

(2017) Intracranial Arterial Dolichoectasia.

Front. Neurol. 8:344.

doi: 10.3389/fneur.2017.00344 sporadic and associated with traditional vascular risk factors including advanced age, male gender, and arterial hypertension. The link between this dilative arteriopathy and other vascular abnormalities, such as abdominal aortic aneurysm, coronary artery ectasia, and cerebral small vessel disease, suggests the underlying diffuse vascular process. Further understanding is needed on the physiopathology of IADE and how to prevent its progression and clinical complications.

Keywords: dolichoectasia, ectasia, dolichosis, dilatative arteriopathy, intracranial arterial dolichoectasia

\section{INTRODUCTION}

Intracranial arterial dolichoectasia (IADE) is an unusual arteriopathy characterized by abnormal elongation, tortuosity, and dilation of the cerebral arteries (2) (Figure 1). Different from the endothelial injury and plaque formation characteristic of atherosclerosis, the tunica media of the arterial wall in patients with IADE is affected by disruption of the internal elastic lamina, atrophy of the muscle layer, and hyalinization of connective tissue, leading to abnormal dilation of the affected blood vessel $(3-5)$. Both, the anterior and posterior cerebral circulation could be affected. However, the basilar artery (BA) is by far the most common affected vessel $(6,7)$. The terms IADE, vertebrobasilar dolichoectasia (VBD), and BA dolichoectasia (BADE) have been used interchangeably in the literature. This might lead to some confusion, as carotid artery ectasia also occurs $(2,8)$.

Intracranial arterial dolichoectasia may be complicated by brain infarction, cranial nerves or brainstem compression, hydrocephalus, intracranial hemorrhage, or death (9-11). IADE has been associated with traditional cerebrovascular risk factors such as advanced age, male gender, arterial hypertension, and history of coronary artery disease $(3,12-14)$. IADE has also been associated with other vascular abnormalities such as abdominal aortic aneurysms $(4,11,15)$, intracranial saccular 


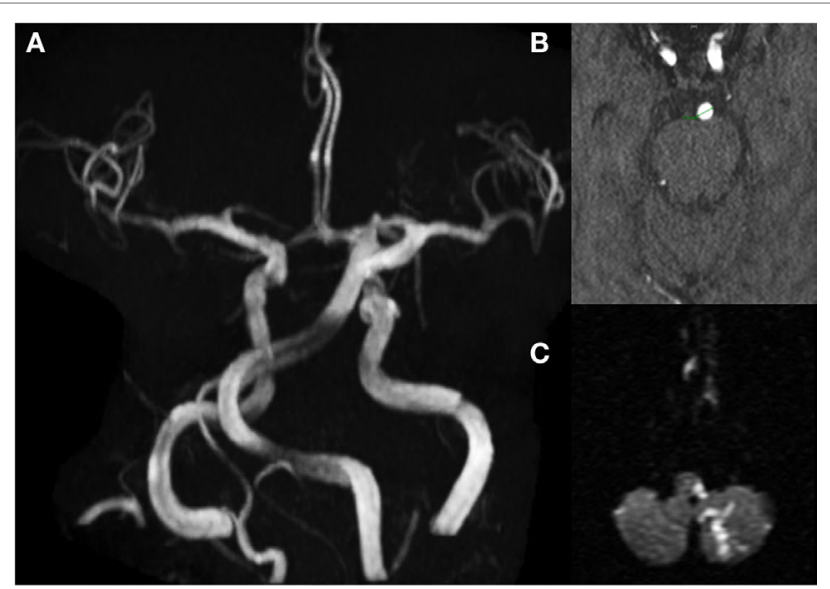

FIGURE 1 | MRI/A brain of a 67-year-old man presenting with left lateral medullary syndrome, and left posterior inferior cerebellar artery (PICA) territory infarct; (A) MRA brain showing elongated and tortuous basilar artery (BA); (B) axial cut showing increased BA diameters $(5.5 \mathrm{~mm})$; (C) diffusion-weight restricted lesion on left PICA territory.

aneurysms $(11,16,17)$, and coronary artery disease with or without coronary artery ectasia $(18,19)$. In addition, a link between IADE and markers of small vessel disease (SVD) has suggested an unidentified common vascular process $(7,20,21)$.

Although little is known about its prognosis, natural course, and how to prevent its complications, IADE is not a benign condition. The lack of validated quantitative criteria has made the study of IADE extremely challenging $(1,12)$. Having standard definitions is imperative to identify high-risk patients in clinical practice, as well as to conduct meaningful and validated research. In this article, we provide a review of available concepts and a discussion of the definition of IADE as well as the prevalence, risk factors, and known complications of this intriguing intracranial arteriopathy.

\section{DEFINITION OF IADE}

The etymology of the word dolichoectasia comes from the Greek dolikhós that means long, and ektasis that literally means distention of a tubular structure (22). There is a spectrum between the normal variations on diameter and tortuosity of cerebral blood vessels and massive aneurysmal dilations leading to serious clinical complications $(10,11)$. Different terms such as mega-artery, mega dolichoartery, fusiform aneurysm, cirsoid aneurysm, serpentiform aneurysm, atherosclerotic aneurysm, and dilatative arteriopathy have been used to describe the abnormal distention and elongation of intracranial arteries (2, 3, 12, 22, 23). Megaartery and mega dolichoartery represent expressions used for gigantic widening of intracranial vessels causing mass effect and pertained to the most severe forms of the disease $(24,25)$. The term aneurysm denotes a localized widen-out due to weakening of the blood vessel wall (26). Intracranial aneurysms could be saccular or non-saccular according to their shape $(26,27)$. Fusiform aneurysm is a form of non-saccular arterial dilation characterized by circumferential ballooning of the entire vessel wall for a short segment (27). The concept of fusiform aneurysm overlaps with the definition of dolichoectasia. However, the later also incorporates the elongation and tortuosity (dolichosis) of an artery in addition to its segmental widening $(27,28)$. Atherosclerotic aneurysm is a misnomer, as arterial dolichoectasia is a distinct arteriopathy from atherosclerosis. However, they do share similar risk factors $(3,7,21)$. Because increased diameter (ectasis) is the most important feature of IADE, dilatative arteriopathy has been used as an alternative name (2).

Intracranial arterial dolichoectasia describes the presence of at least one ectatic and/or enlarged artery in the cerebral vasculature (3). Within the brain, the vertebrobasilar system is preferentially affected $(6,7)$ and probably easier to evaluate on brain imaging than the anterior circulation. For these reasons, VBD and BADE have been preferentially studied and better defined in the literature. Pico and collaborators (3) proposed IADE as a more accurate term to avoid overlooking for anterior circulation pathology. More recently, diffuse IADE, defined as the involvement of two or more cerebral blood vessels, has been suggested as a distinct vascular presentation with a poorer natural history including higher rates of aneurysmal-related death (29).

To determine ectasia, previous investigators have suggested the use of two SD cutoffs based on the maximum diameter of the affected blood vessel $(1,6-8)$. Smoker and colleagues (1) recommended a cutoff of $4.5 \mathrm{~mm}$ diameter at the level of the mid pons to define BA ectasis based on their analysis of 126 CT scans of individuals without underlying brain injury (age ranging from 4 to 85 years). This diameter cutoff has been well accepted (25, 30-35). Gutierrez and collaborators (6) used an arterial diameter of $\geq 2$ SD adjusted for the total cranial volume to define BA ectasis in a large multiethnic cohort and found major variations in the reported frequency when compared to the use of Smoker et al. criteria, visual assessment, and BA volume (4.3 vs 2.9 vs 18.8 vs $2.4 \%$, respectively). For vessels other than the BA, Passero and Rossi have also suggested diameter cutoffs for the internal carotid ( $\geq 7 \mathrm{~mm})$, middle cerebral artery $(\geq 4 \mathrm{~mm})$, and vertebral artery $(\geq 4 \mathrm{~mm})$ to indicate ectasia (10). The evidence of increased clinical complications associated with higher degree of ectasis supports definitions based on arterial diameter $(6,10,11,36)$. For research purposes, the use of arterial diameter as a continuous data rather than a binary categorization would provide more reliable information about the clinical implications of IADE.

Dolichosis refers to the abnormal elongation and tortuosity of an artery. Anatomical landmarks have been used to determine an irregular arterial course. A BA bifurcation at the floor of the third ventricle (above the suprasellar cistern) or a course lateral to the margin of the clivus is considered abnormal (1). The vertebral artery has been considered abnormal if a deviation of $>10 \mathrm{~mm}$ from the shortest expected course or a length $>23.5 \mathrm{~mm}$ exists (31). In order to determine dolichosis of the supraclinoid segment of the internal carotid artery, anterior cerebral artery, middle cerebral artery, and posterior cerebral artery, Gutierrez et al. have proposed a visual assessment based on the compression of surrounding structures and the tortuosity of the vessel when compared with the contralateral artery (37). 
As noticed, an objective definition of IADE has been limited due to the lack of established benchmarks. The development of validated criteria remains challenging due to the lack a gold standard test. Additional studies are needed to better define the cutoffs for pathological IADE in the population.

\section{PREVALENCE}

Table $1(6,16,22,36,38)$ illustrates the reported prevalence among stroke-free patients. Table 2 illustrates the reported prevalence among stroke patients $(7,14,21,39-42)$. One study among the general population considered all large intracranial arteries for the definition of IADE and found that approximately $19 \%$ of individuals 55 years or older had at least one dolichoectatic intracranial artery (6). In this study, the IADE definition was based on the arterial diameter adjusted for head size and involved a multiethnic cohort. However, similar results have not been reproduced by other groups (6). Other large series may have been biased to Asian populations $(16,38)$ or to hospitalized patients undergoing brain MRI for any reason (36). Further studies are needed to elucidate the prevalence of IADE in the general population.

Due to the association of IADE with lacunar infarctions, the prevalence of abnormally dilated arteries may vary according to stroke mechanisms. The occurrence of dolichoectasia is greater when infarctions in the posterior circulation are exclusively considered $(30,32)$. Conversely, the study of Nakamura and colleagues found higher prevalence of dolichoectasia among patients with brain hemorrhages when compared to those with ischemic injuries (12 vs 6\%) (40).

\section{RISK FACTORS}

Arterial dolichoectasia seems to be related to hemodynamic and anatomical factors in the setting of individual-to-individual susceptibility for developing this arteriopathy. Across series, aging, male gender, and arterial hypertension have been consistently associated with $\operatorname{IADE}(6,7,10)$. Other traditional factors such as cigarette smoking, increased body-mass index, dyslipidemia, and diabetes mellitus showed conflicting results $(6,14)$. Due to similar

TABLE 1 | IADE prevalence in series confined to stroke-free patients.

\begin{tabular}{|c|c|c|c|c|}
\hline Reference & Population studied (n) & Definition of dolichoectasia & Diagnostic method & Prevalence (\%) \\
\hline Gutierrez et al. (6) & $\begin{array}{l}\text { Multiethnic cohort of stroke-free individuals } \\
\text { >55 years old (NOMAS) (718) }\end{array}$ & TCV-adjusted arterial diameter $\geq 2$ SD & $\begin{array}{l}\text { MRA + automated } \\
\text { software tool }\end{array}$ & $\begin{array}{l}\text { IADE 18.8, } \\
\text { BADE } 4.3\end{array}$ \\
\hline Tanaka et al. (38) & $\begin{array}{l}\text { Outpatients with atherosclerotic risk factors } \\
>40 \text { years old (493) }\end{array}$ & BA diameter $>4.5 \mathrm{~mm}$ & $\begin{array}{l}\text { T2-weighted MRI, } \\
\text { MRA }\end{array}$ & BADE 0.8. \\
\hline Vasović et al. (22) & Autopsy studies (age range 0-95 years old) (216) & $\begin{array}{l}\text { BA or VA outer diameter }>4.3 \mathrm{~mm} \text {, with or without } \\
\text { deviation from the shortest expected course, and } \\
\text { BA length }>33 \mathrm{~mm}\end{array}$ & Autopsy & VBD 6.5. \\
\hline Ikeda et al. (16) & $\begin{array}{l}\text { Working-class adults living in Tokyo aged } \\
30-90 \text { years old }(7,345)\end{array}$ & BA diameter $>4.5 \mathrm{~mm}$; VA diameter $>4.0 \mathrm{~mm}$ & MRI, MRA & VBD 1.3 \\
\hline Wolfe et al. (36) & $\begin{array}{l}\text { Patients with neuroimaging from a University } \\
\text { Hospital cohort }(1,440)\end{array}$ & $\begin{array}{l}\text { BA diameter }>4.5 \mathrm{~mm} \text {; BA length }>29.5 \mathrm{~mm} \text { or } \\
\text { lateral deviation }>10 \mathrm{~mm} \text {; VA length }>23.5 \mathrm{~mm} \text { or } \\
\text { lateral deviation }>10 \mathrm{~mm}\end{array}$ & MRA & VBD 4.4 \\
\hline
\end{tabular}

BA, basilar artery; BADE, basilar artery dolichoectasia; VA, vertebral artery; VBD, vertebrobasilar dolichoectasia; IADE, intracranial arterial dolichoectasia; TCV, total cranial volume.

TABLE 2 | IADE prevalence in series confined to stroke patients.

\begin{tabular}{|c|c|c|c|c|}
\hline Reference & Population studied ( $n$ ) & Definition of dolichoectasia & $\begin{array}{l}\text { Diagnostic } \\
\text { method }\end{array}$ & Prevalence (\%) \\
\hline $\begin{array}{l}\text { Nakajima } \\
\text { et al. (14) }\end{array}$ & Patients with lacunar strokes (SPS3 trial) $(2,621)$ & BA diameter >4.5 mm; VA diameter $>4.0 \mathrm{~mm}$ & MRA, CTA & VBD 7.6 \\
\hline Park et al. (39) & Patients with ischemic stroke or TIA (182) & $\begin{array}{l}\text { BA diameter }>4.5 \mathrm{~mm} \text {, and either BA bifurcation } \\
\text { above the suprasellar cistern or lateral to the } \\
\text { margin of the clivus (dolichosis) }\end{array}$ & MRA & VBD 13.2 \\
\hline $\begin{array}{l}\text { Nakamura } \\
\text { et al. }(40)\end{array}$ & Patients with acute ischemic and hemorrhagic stroke (481) & BA diameter $>4.5$ mm; VA diameter $>4.0 \mathrm{~mm}$ & MRI, MRA & $\begin{array}{l}\text { VBD } 7.7 \text { (ischemic } \\
\text { stroke } 6.4 \text {; } \\
\text { hemorrhagic stroke } \\
\text { 12.1) }\end{array}$ \\
\hline Pico et al. (21) & Autopsy of patients with ischemic or hemorrhagic stroke (381) & $\begin{array}{l}\text { Enlargement and tortuosity by visual assessment } \\
\text { on pathological examination }\end{array}$ & Autopsy & IADE 6.0 \\
\hline Pico et al. (7) & Caucasian patients with ischemic stroke proven by MRI (510) & Visual assessment & CT, CTA, MRI & IADE 12 \\
\hline Ince et al. (41) & $\begin{array}{l}\text { Patients with ischemic stroke in the community } \\
\text { (The Rochester Epidemiology Project) (387) }\end{array}$ & Visual assessment & $\mathrm{CT}, \mathrm{MRI}$ & IADE 3.1 \\
\hline $\begin{array}{l}\text { Bogousslavsky } \\
\text { et al. (42) }\end{array}$ & Patients with posterior circulation stroke $>45$ years old (70) & Visual assessment & MRI, MRA & VBD 17.1 \\
\hline
\end{tabular}

BA, basilar artery; BADE, basilar artery dolichoectasia; VA, vertebral artery; VBD, vertebrobasilar dolichoectasia; IADE, intracranial arterial dolichoectasia; TCV, total cranial volume. 
risk factors, it has been postulated that IADE and atherosclerosis shared common pathogenesis. The presence of atheromatous plaque associated with IADE seems to happen exclusively in the dolichoectatic vessel and is thought to be a consequence rather than the cause of abnormal blood flow. Conversely, the association of IADE with aortic aneurysm, coronary ectasia, and kinked carotid arteries argues in favor to a generalized susceptibility for arterial dilation.

Wolfe et al. showed increased occurrence among AfricanAmerican patients (36). A study involving a large series of patients with lacunar infarctions demonstrated that white race was independently associated with VBD (14). A multiethnic cohort of a predominantly Hispanic population found a higher prevalence of IADE compared to other reports. However, an ethnic association with IADE has not been fully established (6).

A variety of hereditary conditions including Marfan syndrome, Ehlers-Danlos syndrome type IV, pseudoxanthoma elasticum, neurofibromatosis type 1, tuberous sclerosis complex, Fabry disease, Pompe disease, moyamoya disease, cavernous malformations, autosomal dominant polycystic kidney disease, and the acquired immune deficiency syndrome, have been associated with IADE (43-53).

\section{IADE AND SVD}

Results from two case-control studies found that individuals with stroke and IADE had a higher prevalence of lacunar infarctions (36-42\%) compared to those without IADE (17-19\%) $(7,41)$. In one of these studies, small artery occlusion was the only stroke mechanism associated with IADE (OR 2.89; C.I. 1.29-6.46) (7). When compared with patients without IADE, the same group of investigators found that patients with IADE and ischemic stroke have a higher prevalence of multilacunar state, severe leukoaraiosis, and enlarged perivascular spaces (20). Cerebral microbleeds, another imaging marker of SVD, were more prevalent in stroke patients with IADE than in those without (39). Furthermore, the autopsy study established an association between IADE and sclerosis and hyalinosis of small penetrating arteries (21).

These findings suggest an underlying common physiopathology for IADE and SVD. Abnormal activity of the matrix metalloproteinase family (MMP) has been hypothesized as a potential bridge mechanism between these two conditions (54). MMPs are a family of proteases that act over the extracellular matrix as the rate-limiting step for connective tissue remodeling (55). At the vascular level, MMPs with elastase and collagenase activity (i.e., MMP-2, MMP-3, and MMP-9) have shown to be molecular contributors to aneurysm formation as well as instability of atherosclerotic plaques (55-58). The MMP-3 5A allele, which is associated with an increased proteolytic activity, is found in higher frequency in patients with abdominal aortic aneurysms and coronary artery aneurysms $(57,59,60)$. Pico et al. showed similar results for the MMP-3 5A genotype associated with IADE, implying a role of MMPs in the development of cerebral dilative arteriopathy (54). Conversely, abnormal upregulation of MMPs at the cellular level promote cytotoxicity and central nervous system inflammation by degradation of basal lamina proteins leading to disruption of the blood-brain barrier and breakdown of myelin (61-63). Increased MMPs activity is linked to the pathogenesis of several central nervous system diseases including multiple sclerosis, Alzheimer's disease, and acute stroke $(64,65)$. Among patients with SVD, pathological studies have shown diffuse inflammatory response associated with high levels of MMP3 -positive macrophages in the regions of white matter damage as well as clustering of cells expressing MMP-2 and MMP-3 around the small penetrating vessels (66).

Different physiological and pathological conditions upregulate the expression of MMPs (63). IADE and SVD might have common triggers that activate a cascade of events that lead to an abnormal proteolytic balance turning over in the pathological changes and clinical consequences characteristics of these conditions. These enzymes might represent a potential therapeutic target to modify the natural course of these two cerebrovascular diseases.

\section{CLINICAL COURSE, PROGNOSIS, AND TREATMENT}

Intracranial arterial dolichoectasia can be asymptomatic or may become complicated by one of the following mechanisms: (1) abnormal antegrade laminar blood flow predisposing to thrombi formation with or without embolic phenomena $(33,67)$; (2) occlusion of small penetrating vessels either by stretching and obliteration of arteries raising from the affected vessel or by its association with $\operatorname{SVD}(7,20,41,68)$; (3) compression of surrounding structures including brainstem and cranial nerves (35, 69-73); (4) CSF flow obstruction with resultant hydrocephalus either by direct compression of the third ventricle or by transmission of pulsations causing a "water-hammer" effect $(74,75) ;(5)$ vesselwall rupturewith catastrophicbrainhemorrhages $(17,76,77)$. A systematic review including a total of 375 patients with VBD determined the 5-year risk rate for brain infarction (17.6\%), brainstem compression (10.3\%), transient ischemic attack (10.1\%), hemorrhagic stroke (4.7\%), hydrocephalus (3.3\%), and subarachnoid hemorrhage (2.6\%) (9). The same review reported a 5 -year mortality risk of $36.2 \%$, with ischemic stroke as the most common cause of death (9). Factors associated with adverse clinical outcome include symptoms at the time of diagnosis, severity of arterial dilation and dolichosis, mural T1 signal, mural thrombi, and interval ectasia progression on followup neuroimaging $(9-11,13,36,78)$.

Information on the appropriate management of patients with IADE is scarce. Patients presenting with compressive neurological manifestations should probably have surgical evaluation. Cranial nerve surgical decompression can be achieved by repositioning of the artery (79), while hydrocephalus due to IADE is usually refractory to ventricular shunt placement (8). For patients with cerebrovascular complications, acute management should be based on best care practices for patients with hemorrhagic or ischemic strokes, as no controlled clinical trials have studied the effectiveness of secondary prevention for patients with IADE and stroke $(80,81)$. Anticoagulant use is controversial (82) and might represent additional risk for hemorrhagic complications 
$(17,76)$. Due to the common coexistence with SVD, vascular risk factors control and the use of antiplatelet therapy and statins are advised (3).

Among individuals with newly diagnosed IADE, it is recommended to screen for other potentially fatal arterial disorders including intracranial saccular aneurysms, abdominal aortic aneurysms, and coronary artery disease $(3,11,18,19)$. In young subjects and in those without vascular risk factors, primary predisposing conditions should be considered (i.e., Marfan's, Fabry's, adult-onset Pompe's disease, etc.). Serial imaging at 6 months and then yearly to monitor for arterial enlargement is advised (3). There is no validated stratification according to severity for IADE. Patients at high risk of fatal complications based on severe arterial dilation $(>10 \mathrm{~mm})$ or interval arterial enlargement after diagnosis ( $>2 \mathrm{~mm}$ increase in follow-up imaging) should avoid anticoagulation and have strict blood pressure control $(3,17)$. This subgroup of patients might benefit from surgical repair of the vascular defect. Good outcomes have been reported in studies focused on patients with gigantic dilations (83). Either vessel reconstruction by open surgery $(83,84)$ or endovascular coiling and/or stenting (85) aim to eliminate the risk of bleeding or mass effect without compromising vessel

\section{REFERENCES}

1. Smoker WR, Price MJ, Keyes WD, Corbett JJ, Gentry LR. High-resolution computed tomography of the basilar artery: 1 . Normal size and position. AJNR Am J Neuroradiol (1986) 7(1):55-60.

2. Lou M, Caplan LR. Vertebrobasilar dilatative arteriopathy (dolichoectasia). Ann N Y Acad Sci (2010) 1184:121-33. doi:10.1111/j.1749-6632.2009.05114.x

3. Pico F, Labreuche J, Amarenco P. Pathophysiology, presentation, prognosis, and management of intracranial arterial dolichoectasia. Lancet Neurol (2015) 14(8):833-45. doi:10.1016/S1474-4422(15)00089-7

4. Sacks JG, Lindenburg R. Dolicho-ectatic intracranial arteries: symptomatology and pathogenesis of arterial elongation and distention. Johns Hopkins Med $J$ (1969) 125:95-106.

5. Hegedüs K. Ectasia of the basilar artery with special reference to possible pathogenesis. Surg Neurol (1985) 24(4):463-9. doi:10.1016/0090-3019(85) 90309-X

6. Gutierrez J, Bagci A, Gardener H, Rundek T, Ekind MS, Alperin N, et al. Dolichoectasia diagnostic methods in a multi-ethnic, stroke-free cohort: results from the northern Manhattan study. J Neuroimaging (2014) 24(3): 226-31. doi:10.1111/j.1552-6569.2012.00781.x

7. Pico F, Labreuche J, Touboul PJ, Amarenco P; GENIC Investigators. Intracranial arterial dolichoectasia and its relation with atherosclerosis and stroke subtype. Neurology (2003) 61(12):1736-42. doi:10.1212/01.WNL. 0000103168.14885.A8

8. Yu YL, Moseley IF, Pullicino P, McDonald WI. The clinical picture of ectasia of the intracerebral arteries. J Neurol Neurosurg Psychiatry (1982) 45(1):29-36. doi:10.1136/jnnp.45.1.29

9. Wolters FJ, Rinkel GJ, Vergouwen MD. Clinical course and treatment of vertebrobasilar dolichoectasia: a systematic review of the literature. Neurol Res (2013) 35(2):131-7. doi:10.1179/1743132812Y.0000000149

10. Passero SG, Rossi S. Natural history of vertebrobasilar dolichoectasia. Neurology (2008) 70(1):66-72. doi:10.1212/01.wnl.0000286947.89193.f3

11. Flemming KD, Wiebers DO, Brown RDJr, LinkMJ, Huston JIII, McClellandRL, et al. The natural history of radiographically defined vertebrobasilar nonsaccular intracranial aneurysms. Cerebrovasc Dis (2005) 20(4):270-9. doi:10.1159/ 000087710

12. Gutierrez J, Sacco RL, Wright CB. Dolichoectasia - an evolving arterial disease. Nat Rev Neurol (2011) 7(1):41-50. doi:10.1038/nrneurol.2010.181

13. Nasr DM, Brinjikji W, Rouchaud A, Kadirvel R, Flemming KD, Kallmes DF. Imaging characteristics of growing and ruptured vertebrobasilar non-saccular patency. The technical approach is usually complex and needs to be tailored to each case.

\section{CONCLUSION}

Intracranial arterial dolichoectasia implies a spectrum that includes normal variations in the diameter and tortuosity of the cerebral vasculature as well as gigantic aneurysmal dilations with a high risk of fatal complications. In addition, IADE may involve one or more arteries or may present as a dynamic progressive arteriopathy. All of these factors add to the risk of neurological complications, with ischemic stroke as the most common one. Proposed diagnostic criteria and severity grading based on noninvasive and cost-effective diagnostic tests need to be validated across populations to elucidate the clinical significance of this vasculopathy.

\section{AUTHOR CONTRIBUTIONS}

VB and JO contributed to writing of the manuscript and edited the tables and figures. JB contributed to writing and editing of the manuscript, tables, and figures.

and dolichoectatic aneurysms. Stroke (2016) 47(1):106-12. doi:10.1161/ STROKEAHA.115.011671

14. Nakajima M, Pearce LA, Ohara N, Field TS, Bazan C, Anderson DC, et al. Vertebrobasilar ectasia in patients with lacunar stroke: the secondary prevention of small subcortical strokes trial. J Stroke Cerebrovasc Dis (2015) 24(5):1052-8. doi:10.1016/j.jstrokecerebrovasdis.2014.12.039

15. Pico F, Labreuche J, Cohen A, Touboul PJ, Amarenco P; GENIC Investigators. Intracranial arterial dolichoectasia is associated with enlarged descending thoracic aorta. Neurology (2004) 63:2016-21. doi:10.1212/01. WNL.0000145845.12577.0F

16. Ikeda K, Nakamura Y, Hirayama T, Sekine T, Nagata R, Kano O, et al. Cardiovascular risk and neuroradiological profiles in asymptomatic vertebrobasilar dolichoectasia. Cerebrovasc Dis (2010) 30:23-8. doi:10.1159/ 000313440

17. Passero SG, Calchetti B, Bartalini S. Intracranial bleeding in patients with vertebrobasilar dolichoectasia. Stroke (2005) 36(7):1421-5. doi:10.1161/01. STR.0000172311.64662.9c

18. Pico F, Biron Y, Bousser MG, Amarenco P. Concurrent dolichoectasia of basilar and coronary arteries. Neurology (2005) 65:1503-4. doi:10.1212/01. wnl.0000183285.80271.60

19. Ikeda K, Kashihara H, Hosozawa KI, Tamura M, Baba S, Iwasaki Y. Concurrent dolichoectasia of basilar and coronary arteries. Neurology (2006) 66:1457. doi:10.1212/01.wnl.0000224702.60036.38

20. Pico F, Labreuche J, Touboul PJ, Leys D, Amarenco P. Intracranial arterial dolichoectasia and small-vessel disease in stroke patients. Ann Neurol (2005) 57(4):472-9. doi:10.1002/ana.20423

21. Pico F, Labreuche J, Seilhean D, Duyckaerts C, Hauw JJ, Amarenco P. Association of small-vessel disease with dilatative arteriopathy of the brain: neuropathologic evidence. Stroke (2007) 38(4):1197-202. doi:10.1161/01. STR.0000259708.05806.76

22. Vasović L, Trandafilović M, Jovanović I, Ugrenović S, Vlajković S. Vertebral and/or basilar dolichoectasia in human adult cadavers. Acta Neurochir (Wien) (2012) 154(8):1477-88. doi:10.1007/s00701-012-1400-7

23. Caplan LR. Dilatative arteriopathy (dolichoectasia): what is known and not known. Ann Neurol (2005) 57(4):469-71. doi:10.1002/ana.20447

24. Lodder J, Janevski B, van der Lugt PJ. Megadolicho vascular malformation of the intracranial arteries. Clin Neurol Neurosurg (1981) 83(1):11-8. doi:10.1016/ S0303-8467(81)80004-2

25. Boeri R, Passerini A. The megadolichobasilar anomaly. J Neurol Sci (1964) 1(5):475-84. doi:10.1016/0022-510X(64)90116-9 
26. Meyers PM, Schumacher HC, Higashida RT, Derdeyn CP, Nesbit GM, Sacks D, et al. Reporting standards for endovascular repair of saccular intracranial cerebral aneurysms. JNeurointerv Surg (2010) 2(4):312-23. doi:10.1136/jnis.2010.002337

27. Park SH, Yim MB, Lee CY, Kim E, Son EI. Intracranial fusiform aneurysms: it's pathogenesis, clinical characteristics and managements. J Korean Neurosurg Soc (2008) 44(3):116-23. doi:10.3340/jkns.2008.44.3.116

28. Jaworska K, Dołowy J, Kuśmierska M, Kuniej T, Jaźwiec P. Multiple fusiform cerebral aneurysms - case report. Pol J Radiol (2012) 77(1):50-3. doi:10.12659/ PJR.882581

29. Brinjikji W, Nasr DM, Flemming KD, Rouchaud A, Cloft HJ, Lanzino G, et al. Clinical and imaging characteristics of diffuse intracranial dolichoectasia. AJNR Am J Neuroradiol (2017) 38:915-22. doi:10.3174/ajnr.A5102

30. Kwon HM, Kim JH, Lim JS, Park JH, Lee SH, Lee YS. Basilar artery dolichoectasia is associated with paramedian pontine infarction. Cerebrovasc Dis (2009) 27(2):114-8. doi:10.1159/000177917

31. Ubogu EE, Zaidat OO. Vertebrobasilar dolichoectasia diagnosed by magnetic resonance angiography and risk of stroke and death: a cohort study. J Neurol Neurosurg Psychiatry (2004) 75(1):22-6.

32. Passero S, Filosomi G. Posterior circulation infarcts in patients with vertebrobasilar dolichoectasia. Stroke (1998) 29(3):653-9. doi:10.1161/01. STR.29.3.653

33. Rautenberg W, Aulich A, Röther J, Wentz KU, Hennerici M. Stroke and dolichoectatic intracranial arteries. Neurol Res (1992) 14(2 Suppl):201-3. doi:10.1080/01616412.1992.11740052

34. Milandre L, Bonnefoi B, Pestre P, Pellissier JF, Grisoli F, Khalil R. Vertebrobasilar arterial dolichoectasia. Complications and prognosis. Rev Neurol (Paris) (1991) 147(11):714-22.

35. Smoker WR, Corbett JJ, Gentry LR, Keyes WD, Price MJ, McKusker S. Highresolution computed tomography of the basilar artery: 2. Vertebrobasilar dolichoectasia: clinical-pathologic correlation and review. AJNR Am J Neuroradiol (1986) 7(1):61-72.

36. Wolfe T, Ubogu EE, Fernandes-Filho JA, Zaidat OO. Predictors of clinical outcome and mortality in vertebrobasilar dolichoectasia diagnosed by magnetic resonance angiography. J Stroke Cerebrovasc Dis (2008) 17(6):388-93. doi:10.1016/j.jstrokecerebrovasdis.2008.06.006

37. Gutierrez J, Carrasquillo J, Ortiz G, Wright CB. Vascular profile of dolichoectasia differs depending on the presenting symptoms. Edorium J Cardiol (2014) 1:1-10. doi:10.5348/c03-2014-1-OA-1

38. Tanaka M, Sakaguchi M, Miwa K, Okazaki S, Furukado S, Yagita Y, et al. Basilar artery diameter is an independent predictor of incident cardiovascular events. Arterioscler Thromb Vasc Biol (2013) 33(9):2240-4. doi:10.1161/ ATVBAHA.113.301467

39. Park JM, Koo JS, Kim BK, Kwon O, Lee JJ, Kang K, et al. Vertebrobasilar dolichoectasia as a risk factor for cerebral microbleeds. Eur J Neurol (2013) 20(5):824-30. doi:10.1111/ene.12075

40. Nakamura Y, Hirayama T, Ikeda K. Clinicoradiologic features of vertebrobasilar dolichoectasia in stroke patients. J Stroke Cerebrovasc Dis (2012) 21(1):5-10. doi:10.1016/j.jstrokecerebrovasdis.2010.04.003

41. Ince B, Petty GW, Brown RD Jr, Chu CP, Sicks JD, Whisnant JP. Dolichoectasia of the intracranial arteries in patients with first ischemic stroke: a populationbased study. Neurology (1998) 50(6):1694-8. doi:10.1212/WNL.50.6.1694

42. Bogousslavsky J, Regli F, Maeder P, Meuli R, Nader J. The etiology of posterior circulation infarcts: a prospective study using magnetic resonance imaging and magnetic resonance angiography. Neurology (1993) 43(8):1528-33. doi:10.1212/WNL.43.8.1528

43. Yamada K, Hayakawa T, Ushio Y, Mitomo M. Cerebral arterial dolichoectasia associated with moyamoya vessels. Surg Neurol (1985) 23(1):19-24. doi:10.1016/0090-3019(85)90154-5

44. Schievink WI, Torres VE, Wiebers DO, Huston J III. Intracranial arterial dolichoectasia in autosomal dominant polycystic kidney disease. J Am Soc Nephrol (1997) 8(8):1298-303.

45. Blumenkopf B, Huggins MJ. Tuberous sclerosis and multiple intracranial aneurysms: case report. Neurosurgery (1985) 17(5):797-800. doi:10.1097/ 00006123-198511000-00012

46. Finney LH, Roberts TS, Anderson RE. Giant intracranial aneurysm associated with Marfan's syndrome. Case report. J Neurosurg (1976) 45(3):342-7. doi:10.3171/jns.1976.45.3.0342
47. Kanemoto Y, Hisanaga M, Bessho H. Association of a dolichoectatic middle cerebral artery and an intracranial cavernous hemangioma - case report. Neurol Med Chir (Tokyo) (1998) 38(1):40-2. doi:10.2176/nmc.38.40

48. Laforêt P, Petiot P, Nicolino M, Orlikowski D, Caillaud C, Pellegrini N, et al. Dilative arteriopathy and basilar artery dolichoectasia complicating late-onset Pompe disease. Neurology (2008) 70(22):2063-6. doi:10.1212/01. wnl.0000313367.09469.13

49. Giannantoni NM, Broccolini A, Frisullo G, Pilato F, Profice P, Morosetti R, et al. Neurofibromatosis type 1 associated with vertebrobasilar dolichoectasia and pontine ischemic stroke. J Neuroimaging (2015) 25(3):505-6. doi:10.1111/ jon. 12160

50. Kumar S. Pseudoxanthoma elasticum and cerebral ischemic stroke. Indian J Dermatol Venereol Leprol (2007) 73(6):433-4. doi:10.4103/0378-6323.32746

51. Mahadevan A, Tagore R, Siddappa NB, Santosh V, Yasha TC, Ranga U, et al. Giant serpentine aneurysm of vertebrobasilar artery mimicking dolichoectasia - an unusual complication of pediatric AIDS. Report of a case with review of the literature. Clin Neuropathol (2008) 27(1):37-52. doi:10.5414/NPP27037

52. Kato T, Hattori H, Yorifuji T, Tashiro Y, Nakahata T. Intracranial aneurysms in Ehlers-Danlos syndrome type IV in early childhood. Pediatr Neurol (2001) 25(4):336-9. doi:10.1016/S0887-8994(01)00315-0

53. Goldstein DA, Timpone J, Cupps TR. HIV-associated intracranial aneurysmal vasculopathy in adults. J Rheumatol (2010) 37(2):226-33. doi:10.3899/ jrheum.090643

54. Pico F, Jacob MP, Labreuche J, Soufir N, Touboul PJ, Benessiano J, et al. Matrix metalloproteinase-3 and intracranial arterial dolichoectasia. Ann Neurol (2010) 67(4):508-15. doi:10.1002/ana.21922

55. Loftus IM, Thompson MM. The role of matrix metalloproteinases in vascular disease. Vasc Med (2002) 7(2):117-33. doi:10.1191/1358863x02vm420ra

56. Jones GT, Phillips VL, Harris EL, Rossaak JI, van Rij AM. Functional matrix metalloproteinase-9 polymorphism (C-1562T) associated with abdominal aortic aneurysm. J Vasc Surg (2003) 38(6):1363-7. doi:10.1016/ S0741-5214(03)01027-9

57. Lamblin N, Bauters C, Hermant X, Lablanche JM, Helbecque N, AmouyelP.Polymorphismsin the promoter regions ofMMP-2,MMP-3,MMP-9 and MMP-12 genes as determinants of aneurysmal coronary artery disease. J Am Coll Cardiol (2002) 40(1):43-8. doi:10.1016/S0735-1097(02)01909-5

58. Sho E, Sho M, Singh TM, Nanjo H, Komatsu M, Xu C, et al. Arterial enlargement in response to high flow requires early expression of matrix metalloproteinases to degrade extracellular matrix. Exp Mol Pathol (2002) 73(2):142-53. doi:10.1006/exmp.2002.2457

59. Newman KM, Ogata Y, Malon AM, Irizarry E, Gandhi RH, Nagase H, et al. Identification of matrix metalloproteinases 3 (stromelysin-1) and 9 (gelatinase B) in abdominal aortic aneurysm. Arterioscler Thromb (1994) 14(8):1315-20. doi:10.1161/01.ATV.14.8.1315

60. Curci JA, Liao S, Huffman MD, Shapiro SD, Thompson RW. Expression and localization of macrophage elastase (matrix metalloproteinase-12) in abdominal aortic aneurysms. J Clin Invest (1998) 102(11):1900-10. doi:10.1172/JCI2182

61. Chandler S, Coates R, Gearing A, Lury J, Wells G, Bone E. Matrix metalloproteinases degrade myelin basic protein. Neurosci Lett (1995) 201(3):223-6. doi:10.1016/0304-3940(95)12173-0

62. Weekman EM, Wilcock DM. Matrix metalloproteinase in blood-brain barrier breakdown in dementia. J Alzheimers Dis (2016) 49(4):893-903. doi:10.3233/ JAD-150759

63. Rosenberg GA. Neurological diseases in relation to the blood-brain barrier. J Cereb Blood Flow Metab (2012) 32(7):1139-51. doi:10.1038/jcbfm.2011.197

64. Yong VW, Krekoski CA, Forsyth PA, Bell R, Edwards DR. Matrix metalloproteinases and diseases of the CNS. Trends Neurosci (1998) 21(2):75-80. doi:10.1016/S0166-2236(97)01169-7

65. Romi F, Helgeland G, Gilhus NE. Serum levels of matrix metalloproteinases: implications in clinical neurology. Eur Neurol (2012) 67(2):121-8. doi: $10.1159 / 000334862$

66. Rosenberg GA, Sullivan N, Esiri MM. White matter damage is associated with matrix metalloproteinases in vascular dementia. Stroke (2001) 32(5):1162-8. doi:10.1161/01.STR.32.5.1162

67. Hennerici M, Rautenberg W, Schwartz A. Transcranial Doppler ultrasound for the assessment of intracranial arterial flow velocity - Part 2. Evaluation of intracranial arterial disease. Surg Neurol (1987) 27(6):523-32. doi:10.1016/0090-3019(87)90251-5 
68. Kumral E, Kisabay A, Ataç C, Kaya C, Calli C. The mechanism of ischemic stroke in patients with dolichoectatic basilar artery. Eur J Neurol (2005) 12(6):437-44. doi:10.1111/j.1468-1331.2005.00993.x

69. Rahman EA, Trobe JD, Gebarski SS. Hemifacial spasm caused by vertebral artery dolichoectasia. Am J Ophthalmol (2002) 133(6):854-6. doi:10.1016/ S0002-9394(02)01387-9

70. Goldenberg-Cohen N, Miller NR. Noninvasive neuroimaging of basilar artery dolichoectasia in a patient with an isolated abducens nerve paresis. Am J Ophthalmol (2004) 137(2):365-7. doi:10.1016/S0002-9394(03)00898-5

71. Guirgis MF, Lam BL, Falcone SF. Optic tract compression from dolichoectatic basilar artery. Am J Ophthalmol (2001) 132(2):283-6. doi:10.1016/ S0002-9394(01)00869-8

72. Castelnovo G, Jomir L, Le Bayon A, Bouly S, Thiebaut C, Labauge P. Lingual atrophy and dolichoectatic artery. Neurology (2003) 61(8):1121. doi:10.1212/ WNL.61.8.1121

73. Savitz SI, Ronthal M, Caplan LR. Vertebral artery compression of the medulla. Arch Neurol (2006) 63(2):234-41. doi:10.1001/archneur.63.2.234

74. Ekbom K, Greitz T, Kugelberg E. Hydrocephalus due to ectasia of the basilar artery. J Neurol Sci (1969) 8(3):465-77. doi:10.1016/0022-510X(69)90006-9

75. Siddiqui A, Chew NS, Miszkiel K. Vertebrobasilar dolichoectasia: a rare cause of obstructive hydrocephalus: case report. Br J Radiol (2008) 81(964):e123-6. doi:10.1259/bjr/27603660

76. Rabb CH, Barnwell SL. Catastrophic subarachnoid hemorrhage resulting from ruptured vertebrobasilar dolichoectasia: case report. Neurosurgery (1998) 42(2):379-82. doi:10.1097/00006123-199802000-00108

77. De Georgia M, Belden J, Pao L, Pessin M, Kwan E, Caplan L. Thrombus in vertebrobasilar dolichoectatic artery treated with intravenous urokinase. Cerebrovasc Dis (1999) 9(1):28-33. doi:10.1159/000015892

78. Mangrum WI, Huston J III, Link MJ, Wiebers DO, McClelland RL, Christianson TJ, et al. Enlarging vertebrobasilar nonsaccular intracranial aneurysms: frequency, predictors, and clinical outcome of growth. J Neurosurg (2005) 102(1):72-9. doi:10.3171/jns.2005.102.1.0072

79. Ferreira M, Walcott BP, Nahed BV, Sekhar LN. Vertebral artery pexy for microvascular decompression of the facial nerve in the treatment of hemifacial spasm. J Neurosurg (2011) 114(6):1800-4. doi:10.3171/2010.12.JNS10891
80. Powers WJ, Derdeyn CP, Biller J, Coffey CS, Hoh BL, Jauch EC, et al. 2015 American Heart Association/American Stroke Association focused update of the 2013 guidelines for the early management of patients with acute ischemic stroke regarding endovascular treatment: a guideline for healthcare professionals from the American Heart Association/American Stroke Association. Stroke (2015) 46(10):3020-35. doi:10.1161/STR.0000000000000074

81. Hemphill JC III, Greenberg SM, Anderson CS, Becker K, Bendok BR, Cushman M, et al. Guidelines for the management of spontaneous intracerebral hemorrhage: a guideline for healthcare professionals from the American Heart Association/American Stroke Association. Stroke (2015) 46(7):2032-60. doi:10.1161/STR.0000000000000069

82. Drake CG, Peerless SJ. Giant fusiform intracranial aneurysms: review of 120 patients treated surgically from 1965 to 1992. J Neurosurg (1997) 87(2):141-62. doi:10.3171/jns.1997.87.2.0141

83. Anson JA, Lawton MT, Spetzler RF. Characteristics and surgical treatment of dolichoectatic and fusiform aneurysms. J Neurosurg (1996) 84(2):185-93. doi:10.3171/jns.1996.84.2.0185

84. Lin YW, Chen CH, Lai ML. The dilemma of treating vertebrobasilar dolichoectasia. Clin Pract (2012) 2(4):e84. doi:10.4081/cp.2012.e84

85. Suh SH, Kim BM, Chung TS, Kim DI, Kim DJ, Hong CK, et al. Reconstructive endovascular treatment of intracranial fusiform aneurysms: a 1-stage procedure with stent and balloon. AJNR Am J Neuroradiol (2010) 31(1):155-60. doi:10.3174/ajnr.A1784

Conflict of Interest Statement: The authors declare that the research was conducted in the absence of any commercial or financial relationships that could be construed as a potential conflict of interest.

Copyright (C) 2017 Del Brutto, Ortiz and Biller. This is an open-access article distributed under the terms of the Creative Commons Attribution License (CC BY). The use, distribution or reproduction in other forums is permitted, provided the original author(s) or licensor are credited and that the original publication in this journal is cited, in accordance with accepted academic practice. No use, distribution or reproduction is permitted which does not comply with these terms. 